\title{
Thioredoxin Reductase 1 Expression in Colon Cancer: Discrepancy between In Vitro and In Vivo Findings
}

\author{
Sandra Lechner, Ulf Müller-Ladner, Elena Neumann, Tanja Spöttl, \\ Klaus Schlottmann, Josef Rüschoff, Jürgen Schölmerich, and Frank Kullmann
}

\author{
Department of Internal Medicine I (SL, UM-L, EN, TS, KS, JS, FK), University of Regensburg, Regensburg, and \\ Institute of Pathology (JR), Klinikum Kassel, Kassel, Germany
}

\begin{abstract}
SUMMARY: Thioredoxin and thioredoxin reductase 1 (TR1) are redox proteins that have been implicated in cellular events such as proliferation, transformation, and apoptosis. Analysis of the expression and localization of TR1 in different normal and cancer cell lines and in colon tissues (normal, neoplastic, or inflamed) was performed using reverse transcription-PCR and in situ hybridization. TR1 mRNA was expressed in all analyzed tissues with TR mRNA-positive cells restricted to the stroma of colon crypts, partly being CD3 or CD56 positive. In neoplastic areas of colonic cancer tissue, a loss of TR was obvious. None of the epithelial cells in colonic mucosa expressed TR mRNA, whereas more than $70 \%$ of HT-29 cells grown in monolayer were positive for TR. In contrast, HT-29 cells, grown as spheroids or as tumors in SCID mice, were negative for TR. In contrast to these in vitro findings and previous studies, there is no evidence that TR plays a significant role in vivo in normal cell growth in colonic epithelial cells. The mechanism underlying the loss of TR1-positive/CD3-positive/CD56-positive cells or the biologic consequence of this phenomenon observed in neoplastic colonic tissue remains to be clarified. (Lab Invest 2003, 83:1321-1331).
\end{abstract}

$$
T^{\text {h }}
$$
he thioredoxin reductases (TRs) are enzymes that belong to the flavoprotein family of pyridine nucleotide-disulfide oxidoreductases that includes lipoamide dehydrogenase, glutathione reductase, and mercuric ion reductase (Mustacich and Powis, 2000). TR catalyzes the NADPH-dependent reduction of thioredoxins (Trxs), a group of small (10 to 12-kd) and widely distributed redox active peptides that have a conserved-Trp-Cys-Gly-Pro-Cys-Lys-catalytic site that undergoes reversible oxidation and reduction of the two Cys residues (Freemerman et al, 1999; Oblong et al, 1994). Trx was identified originally because of its ability to serve as a cofactor for ribonucleotide reductase, the first unique step in DNA synthesis (Laurent et al, 1964). Furthermore, Trx has been shown to exert redox control over a number of transcription factors, modulating their DNA binding, and resulting finally in the regulation of gene transcription (Powis et al, 1995). Transcription proteins whose activity is modulated directly by Trx include nuclear factor $-\kappa \mathrm{B}$ (Hirota et al, 1999), TFIIIC (Cromlish and Roeder, 1989), BZLF1 (Bannister et al, 1991), and the glucocorticoid receptor (Grippo et al, 1985). The transcription factor activator protein-1 (AP-1; Fos/Jun heterodimer) is subject to redox control by the redox factor Ref-1, which, in turn, is reduced by Trx (Abate et al, 1990; Karimpour et al,

\section{DOI: 10.1097/01.LAB.0000085189.47968.F8}

Received June 9, 2003.

This study was supported by German Research Society grants (DFG no. Ku 1024/6-1, Ku 1024/6-3, and Mu 1383/1-3).

Address reprint requests to: Dr. Frank Kullmann, Department of Internal Medicine I, University of Regensburg, D-93042 Regensburg, Germany. E-mail: frank.kullmann@klinik.uni-regensburg.de
2002). Recently it was found that TR is a member of the genes associated with retinoid-IFN-induced mortality family (Hofmann et al, 1998). IFN- $\beta$ and all-trans retinoic acid-induced regulation of p53 dependent gene expression requires TR (Hu et al, 2001), which has to be intact (Merwin et al, 2002).

The first mammalian TR (TR1) was cloned from human placenta and showed only a $31 \%$ sequence identity with prokaryotic TR as well as $44 \%$ sequence identity with eukaryotic and prokaryotic glutathione reductases (Gasdaska et al, 1995b). The gene for TR1 was mapped to chromosome 12q23-q24.1 (Gasdaska et al, 1996) and has similar overall structure to that of glutathione reductase (GR) (Sandalova et al, 2001). A second human TR (TR2), showing an $84 \%$ similarity at the protein level to TR1, has recently been cloned (Gasdaska et al, 1999b; Miranda-Vizuete et al, 1999). The gene for human TR2 is located on chromosome 22q11.2 (Miranda-Vizuete et al, 1999). At present, the function of TR2 is elusive, but there is substantial evidence that it may be involved in protecting cells against mitochondrial-mediated oxidative stress (Spyrou et al, 1997). Actual data suggest that TR2 participates in the regulation of protein tyrosine phosphorylation and cell growth as a component of the mitochondria-specific $\mathrm{H}_{2} \mathrm{O}_{2}$-eliminating system that includes peroxiredoxin III and thioredoxin 2 (Kim et al, 2003).

As published previously, Trx has been shown to play an important role in regulating cancer cell growth and inhibiting apoptosis (Gasdaska et al, 1995a; Powis et al, 1995). Therefore, it would be reasonable that TR also plays a role in regulating cell growth. In one study, a panel of six human tumor cell lines were 
found to exhibit a 23-fold range in the levels of TR mRNA (Berggren et al, 1996). In the same study, human primary colorectal tumors were compared with corresponding normal colonic mucosa showing TR protein activity higher in the tumors but only approximately 2-fold (Berggren et al, 1996).

Because of the potential importance of expression of TR on cell growth regulation on the one hand and a lack of knowledge about expression in cancer tissue on the other hand, we studied the expression and localization of TR1 mRNA in colorectal cancer tissue by in situ hybridization. The findings of mRNA expression were confirmed by protein measurement using immunohistochemistry. We furthermore examined the expression of TR1 in different cancer cell lines and normal cells such as primary colonic epithelial cells.

\section{Results}

\section{TR1 mRNA Expression in Different Human Cancer Cell Lines, Colorectal Cancer Tissue, and Normal Cells}

A panel of 10 human tumor cell lines, colonic fibroblasts, scleroderma fibroblasts, and keratinocytes were found to exhibit a 44-fold range in TR1 mRNA levels (Fig. 1). In four independent semiquantitative reverse transcription-PCR (RT-PCR) reactions, the highest level of TR1 mRNA was found in the fibrosarcoma cell line HT1080 (3.7 \pm 0.78 , mean \pm SEM; Fig. 1A). The gastric cancer cell line $23132 / 87$ (1.4 \pm 0.23$)$ and A549 (1.0 \pm 0.33; lung cancer) also expressed relatively high levels of $\mathrm{TR} 1 \mathrm{mRNA}$. With respect to colon cancer, the mismatch repair-deficient colon cancer cell lines HCT-15 (0.4 \pm 0.05$)$ and LoVo $(0.4 \pm$ 0.03) expressed more TR1 mRNA than HT-29, SW480, or SW620 (0.2 $\pm 0.03,0.08 \pm 0.03,0.03 \pm 0.01)$ but not substantially more than nonmalignant cells (colonic fibroblasts $[0.3 \pm 0.11]$ or keratinocytes $[0.5 \pm$ $0.28])$. The cell lines BT20 (0.2 \pm 0.11 , breast cancer) and Caki1 (0.1 0.03 , kidney cancer) expressed negligible amounts of TR1 mRNA (Fig. 1). In all four paired samples of colon cancer tissue and normal mucosa, an apparent up-regulation of TR1 mRNA in the neoplastic tissue could be observed (Fig. 2). In these experiments, the RNA was prepared without microdissection from the whole cancer or normal tissue.

\section{In Situ Expression of TR1 in Cancer Cell Lines and Colonic Tissue}

Approximately $70 \%$ of epithelial cells (HT-29 colon cancer cell line), grown in monolayer, showed a positive in situ signal for the isolated TR1 gene segment, confirming TR1 mRNA production observed in RTPCR experiments. The in situ signal was strongly located in the cytoplasm of the cells. Figure 3 shows HT-29 cells intensively expressing mRNA for TR1. It is interesting that large conglomerates of HT-29 cells (subconfluent cells) were almost TR1 negative. The experiments were performed with the fibrosarcoma cell line HT1080 as well. There were no relevant differences in comparison with HT-29 cells regarding

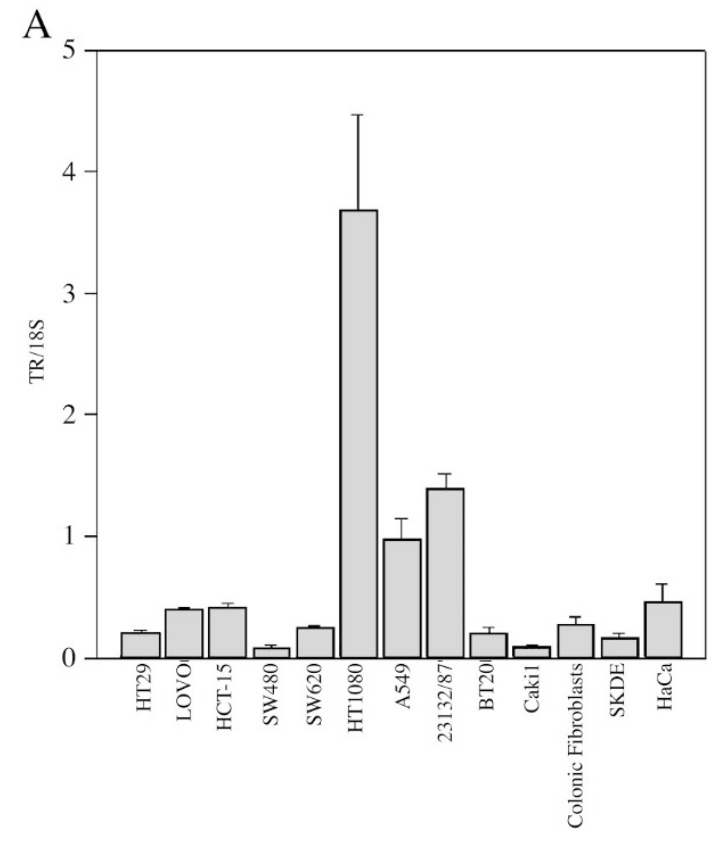

B

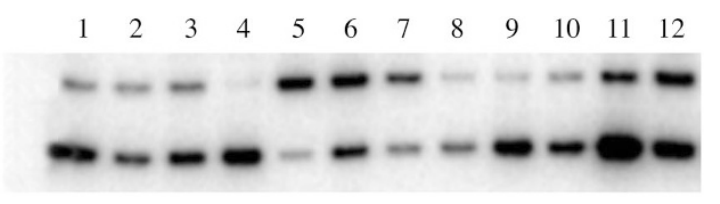

Figure 1.

A, Relative expression (thioredoxin reductase [TR]/18S) of TR1 mRNA in 10 human cancer cell lines, colonic fibroblasts, scleroderma fibroblasts, and keratinocytes. The bars represent four independent reverse transcription-PCR (RT-PCR) reactions \pm SEM. B, Example of a semiquantitative RT-PCR of the TR1 mRNA using 18S rRNA as internal standard: 1, HT-29; 2, LoVo; 3, HCT-15; 4, SW480; 5, HT1080; 6, A549; 7, 23132/87; 8, BT20; 9, Caki1; 10, fibroblasts of the intestine; 11, SKDE; 12, HaCa.

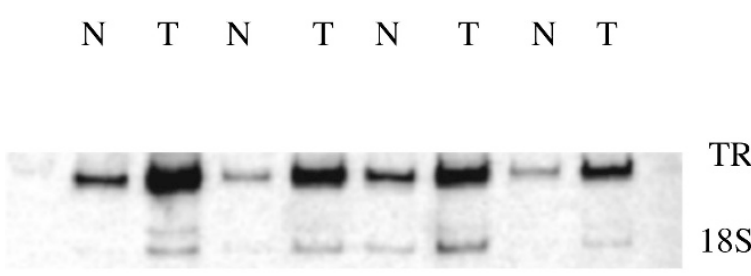

Figure 2.

Expression of four paired samples (whole section without microdissection) of colon tumor and normal mucosa analyzed by semiquantitative RT-PCR using 18S rRNA as internal standard.

the number of positive cells or the expression pattern (data not shown).

Using the same TR probe as in the cell culture experiments, we found positive hybridization signals for TR1 mRNA in all tissue sections (normal, inflammatory, and neoplastic colonic mucosa). Surprising, none of the epithelial cells showed a TR1 mRNA expression independently whether normal, inflammatory, or neoplastic colonic mucosa was hybridized. In contrast, intensive TR1 mRNA expression could be observed in the stroma between the crypts of normal colonic mucosa (Fig. 4, A and B). Sections of colon 


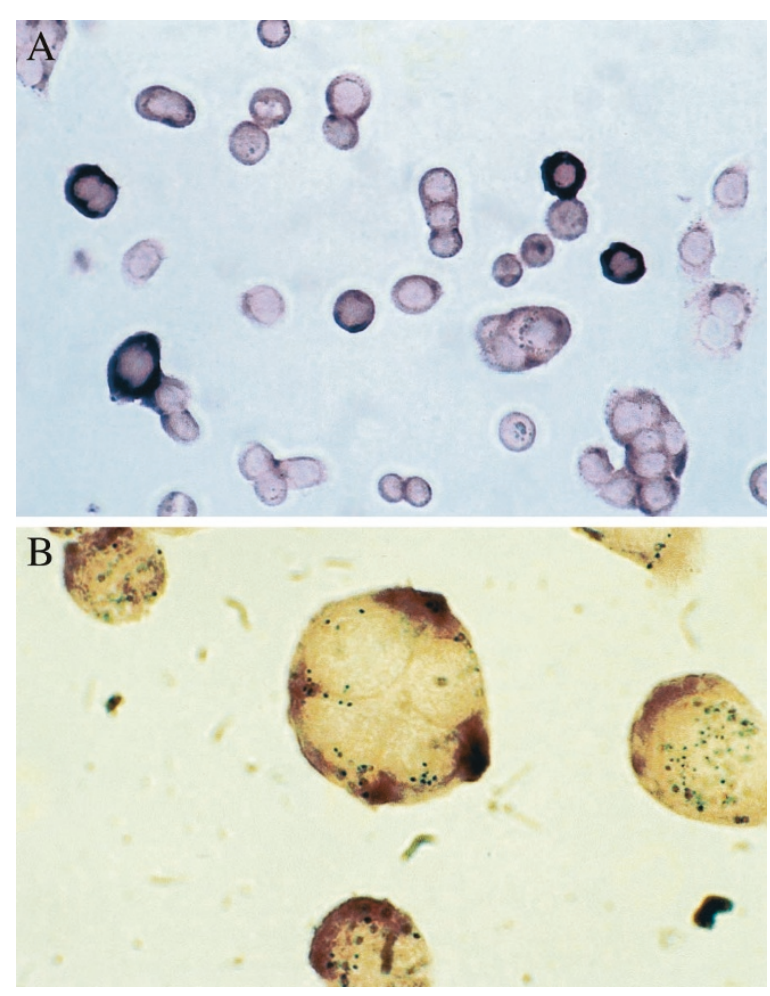

Figure 3.

Demonstration of TR1 mRNA in HT-29 cells by in situ hybridization. A, TR1-positive cells (to get a general idea of the number of positive cells). B, Intensive cytoplasmic signal for the TR probe. Original magnifications, $\times 400$ (A) and $\times 1000(B)$.

cancer tissues showed a high number of TR-positive cells in nonneoplastic areas that were adjacent to the neoplastic areas but an unequivocally reduced number of TR1-positive cells in preneoplastic and neoplastic areas (Fig. 4C). Of interest, the most intensive TR1 mRNA expression was found within inflammatory infiltrates of Crohn's disease. To clarify the origin of the TR1-positive cells, we performed double labeling using different mAb. TR1 mRNA expressing cells could be in part double labeled with a CD3 antibody, indicating that the TR1 mRNA expressing cells consist partially of lymphocytes (Fig. 4D). Some of the TRpositive cells were positive for CD56. None of the cells that were positive for TR1 mRNA could be double labeled with CD45, CD68, or collagen type IV.

On the basis of the observation that subconfluent cells were negative for TR1, we postulated that the loss of cell-cell interactions might result in a stressinduced up-regulation of TR1 mRNA expression in cell culture. Therefore, we cultured HT-29 cells as spheroids or tumors in SCID mice and performed in situ hybridization for TR1 mRNA. The cell aggregates of the spheroids after 6 days of cultivation (Fig. 5), as well as the SCID tumors (Fig. 6), showed no in situ signal. After 11 days, the aggregates of the spheroids started to become necrotic in the centrum, and around this area, a small number of TR1-positive cells could be observed (Fig. 5).

\section{TR mRNA in Colorectal Cancer Tissue after Microdissection}

As the next step, it was essential to clarify whether the up-regulation of TR1 mRNA expression observed in colon cancer tissue in comparison with corresponding normal colonic tissue was induced by "contaminating" cells such as lymphocytes. Therefore, we performed laser capture microdissection on epithelial cells of colon cancer tissue to exclude a mixed cell population in the PCR reaction. The results of these experiments are shown in Figure 7. As suspected, microdissected epithelial cells of colon cancer tissue expressed in comparison with HT-29 or HT-1080 negligible amounts of TR1 mRNA. In addition, fresh isolated primary colonic epithelial cells from normal mucosa expressed TR mRNA on a very low level, too, as shown in Figure 8.

\section{Validation of mRNA with Immunohistochemistry}

To confirm further the reliability of our mRNA data, we performed immunohistochemical analysis of TR1 protein using tissue of the four different patients with colorectal cancer. In accordance with the expression pattern observed on mRNA level, the normal colonic crypt cells (Fig. 9A, negative contol 9B) as well as the corresponding neoplastic colonic crypt cells (Fig. 9C, negative control 9D) showed no immunoreactivity for TR1, whereas stromal cells of normal (Fig. 9A) and malignant tissue sections (Fig. 9C) showed a clear immunoreactivity for TR1. These results further support the reliability of our mRNA data of TR1 expression in vivo.

\section{Discussion}

The current view on the role of TR indicates an important role in regulating biologic functions such as cell growth and cell death that had, to date, centered around its role as a reductant for Trx. On the basis of the ability of exogenous and transfected Trx to stimulate cell growth or inhibit apoptosis, it has been proposed that the TR-Trx system acts as a growth promotor (Baker et al, 1997; Gallegos et al, 1996). Trx has to be in its reduced form to exert this effect, and mutant redox-inactive forms of Trx are unable to stimulate cell growth or inhibit apoptosis (Freemerman et al, 1999). Trx is also known as adult T-cell-derived leukemic growth factor, because it has been isolated as a stimulus of leukemic cell growth (Yodoi and Tursz, 1991). In contrast, several reports indicate that TR and Trx are growth inhibitors (Deiss and Kimchi, 1991; Hofmann et al, 1998), which is reflected by the fact that Trx induced apoptosis in murine WEHI cells (Baker et al, 1997) and inhibited the growth of certain hepatoma cells (Rubartelli et al, 1995). These conflicting observations raise the question of the specific role of TR1 in normal cell growth and tumorigenesis.

To evaluate new aspects in this scenario, we investigated the expression and localization of TR1 mRNA in colorectal cancer tissue using different molecular techniques. First, we analyzed TR1 mRNA expression 

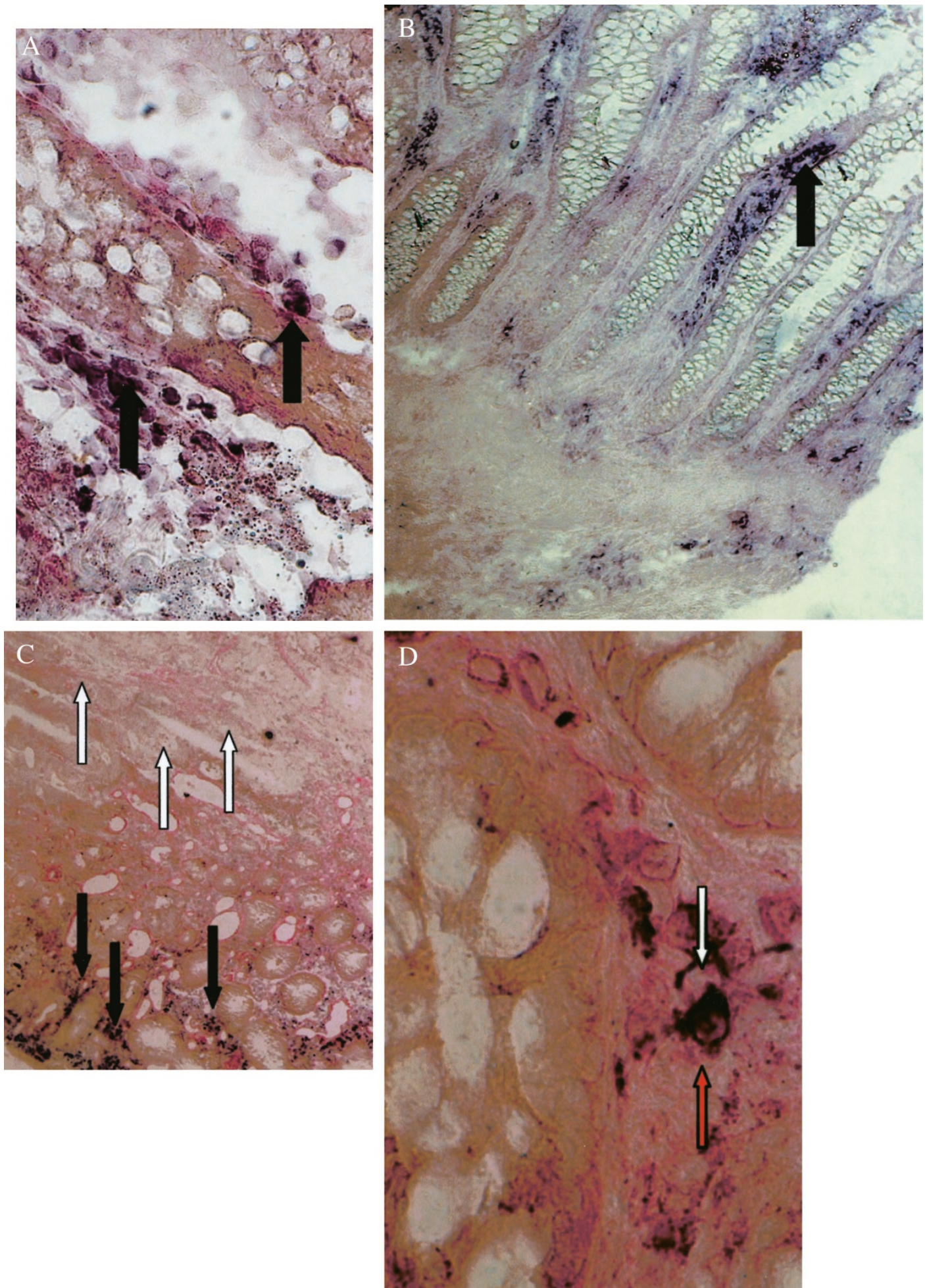

Figure 4.

Demonstration of TR1 mRNA in colonic tissue by in situ hybridization. A and B, Normal colonic tissue, arrows indicate TR1 mRNA-positive cells (black staining). None of the epithelial cells showed a TR1 mRNA expression. TR1 mRNA expression was found in the stroma, between the colon crypts. C, Neoplastic colonic tissue with TR1-positive cells in nontumor areas (black arrows) and without any hybridization signal in the neoplastic area (white arrows). D, Normal colonic tissue with a TR1-positive cell (in situ hybridization, black staining; black arrow) showing also a CD3-positive signal (immunohistochemistry, red staining; red arrow). Original magnifications, $\times 400(A), \times 100(B, C), \times 800(D)$.

in a panel of 10 human tumor cell lines, colonic fibroblasts, scleroderma fibroblasts, and keratinocytes and found a wide variety in TR mRNA expres- sion (up to 44-fold; Fig. 1). In accordance with Berggren et al (1996), we observed a high level of TR1 mRNA in renal cancer cell lines and substantially lower 


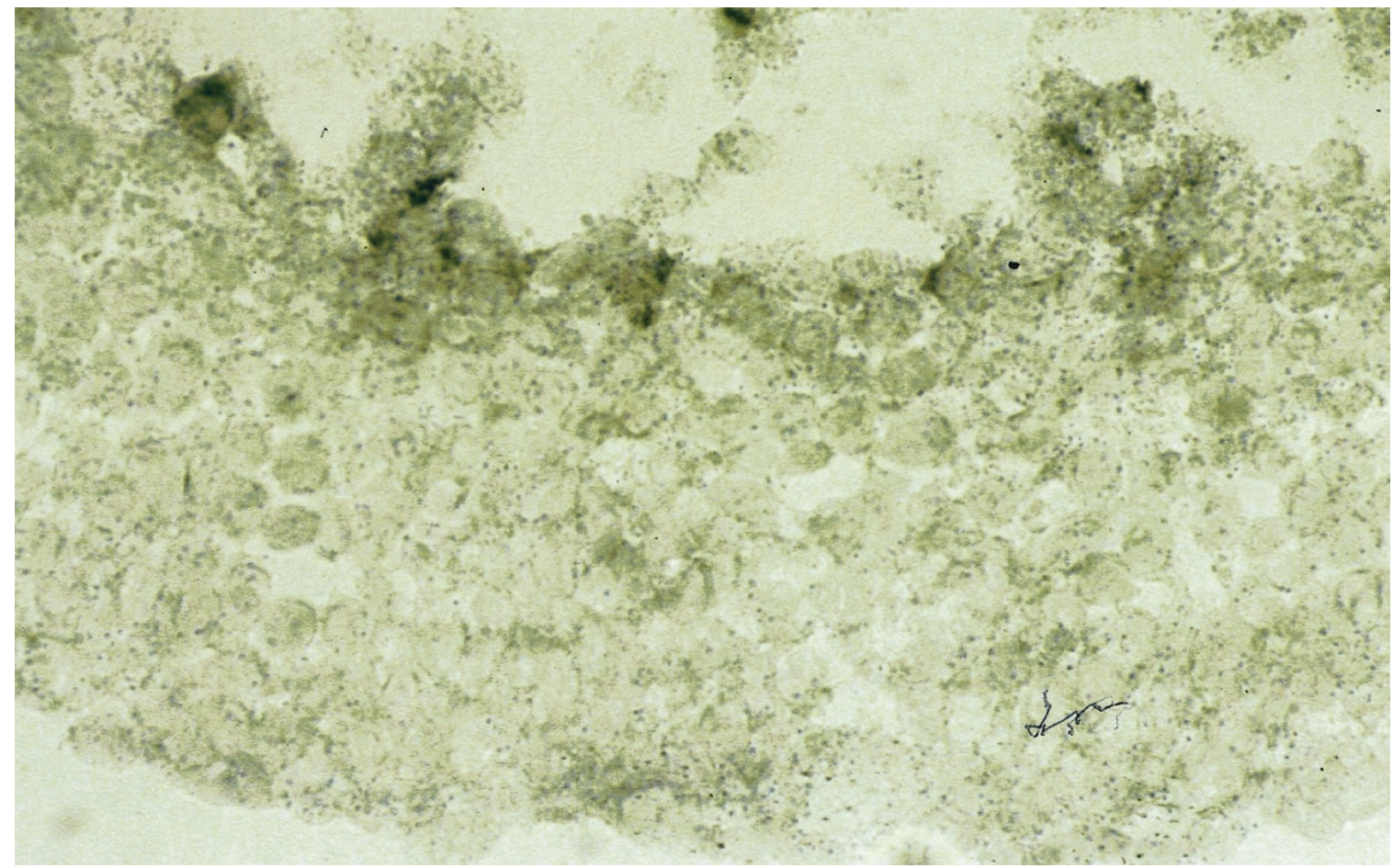

Figure 5 .

Spheroids of HT-29 cells (11 days). Demonstration of TR1 mRNA in HT-29 by in situ hybridization. HT-29 cells show almost no expression of TR1 mRNA. In the centrum of the spheroid (starting necrosis), there are some positive cells. Original magnification, $\times 100$.

TR1 expression in colon and breast cell lines. With respect to colon cancer, the mismatch repair-deficient colon cancer cell lines HCT-15 and LoVo expressed more TR1 mRNA than HT-29, SW480, or SW620 but not essentially more than nonmalignant cells (colonic fibroblasts or keratinocytes). At this point, it has to be mentioned that selenium (Se) is essential for the activity of TR1, and adding Se at $10 \mu \mathrm{m}$ to the medium of cultured cells increases cellular TR1 activity by as much as 60-fold (Berggren at al, 1997; Gallegos et al, 1997). In vitro and in vivo studies described a missing relation between TR activity and TR1 mRNA expression (Hadley and Sunde, 2001; Hara et al, 2001; Wu et al, 2003), which might be influenced by the origin of the cell (Miller et al, 2002). Consequently, we cannot exclude an relevant impact by Se on our mRNA expression data, because all of our cell culture experiments were performed in medium that was not Se supplemented. Nevertheless, our results indicate that culturing of some tumor cell lines is accompanied by an up-regulation of TR1 mRNA expression, but this effect on the transcriptional level is not a hallmark of malignancy. More evidence for the latter was that paired samples of colon cancer tissue and normal mucosa showed an apparent up-regulation of TR1 mRNA (after mRNA preparation without microdissection) in the neoplastic tissue that was already reported on the protein level (Berggren et al, 1996). TR has also been shown to be elevated in human primary melanoma, which was correlated with invasiveness (Schallreuter et al, 1991). Matching with these observations, $70 \%$ of epithelial cells (HT-29 colon cancer cell line), grown in monolayers, showed a positive in situ signal for the TR1 gene segment (Fig. 3).

On the basis of these data, it was absolutely unexpected that none of the epithelial cells showed a positive TR1 mRNA expression independently whether normal, inflammatory, or neoplastic colonic mucosa was hybridized with the same probe as used in cell culture experiments. The TR1-positive cells were predominantly localized in the stroma between the crypts of normal colonic mucosa (Fig. 4, A and B). In sections of colon cancer, tissues showed a high number of TR1-positive cells in nonneoplastic areas that were adjacent to the neoplastic areas when compared with a lower number of TR1positive cells in preneoplastic and neoplastic areas (Fig. 4C). Double staining identified these cells to be at least partially CD3 positive (Fig. 4D). In this context, it is of interest that Trx, which is based on the predicted amino acid sequence identical to that of the autocrine growth factor human adult T-cell-derived factor, is produced by human lymphocytes and HTLV-1 transformed T-cells (Tagaya et al, 1989; Wakasugi et al, 1990; Yodoi and Tursz, 1991). Our results also indicate that at least studies using colon cancer cell lines (Berggren et al, 1996) and investigated regulation of TR1 mRNA expression produced artificial results showing an up-regulation. The data of spheroids (Fig. 5) and SCID tumors (Fig. 6) support the speculation that the up-regulation of TR1 mRNA is the result of stress, induced by loss of the interaction between the cells and extracellular matrix proteins (Powis et al, 1995). It is obvious that TR1 plays in vivo no significant role in normal cell growth processes in colonic epithelial cells. Microdissected epithelial cells 


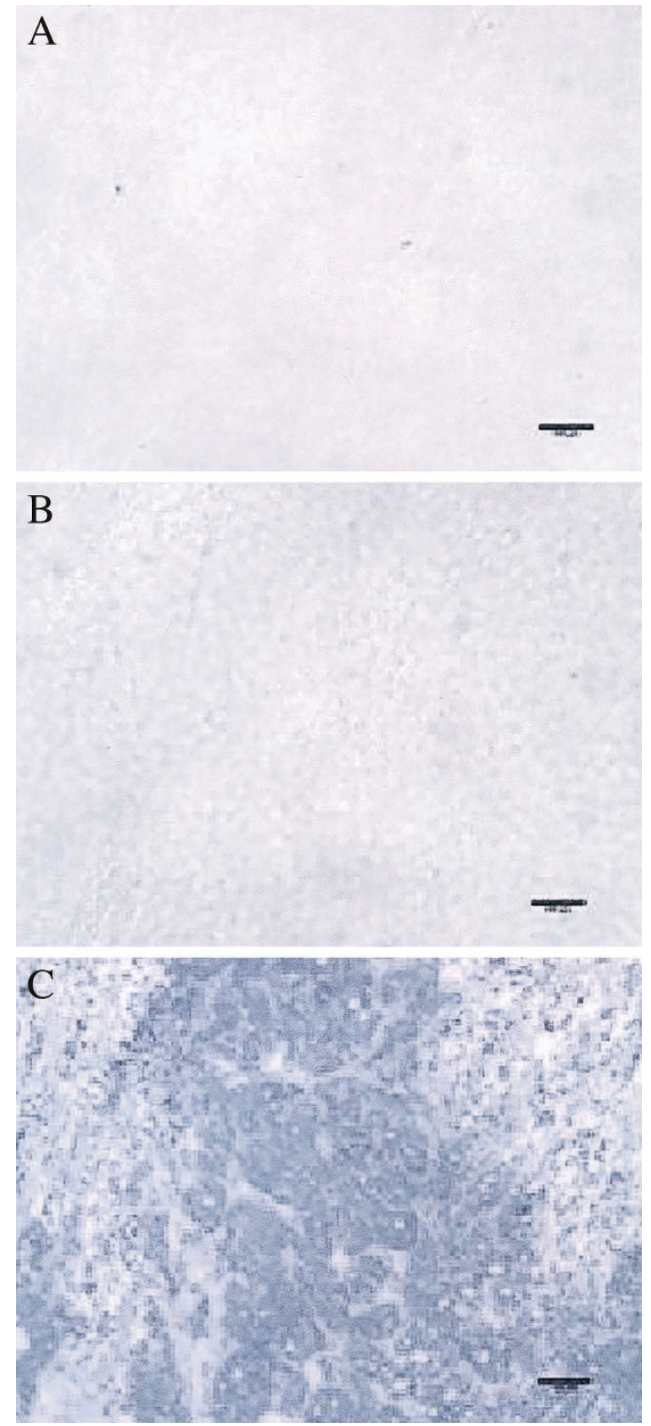

Figure 6.

SCID tumors of HT-29 cells. Demonstration of absent TR1 mRNA in HT-29 grown as tumor in SCID mice by in situ hybridization. $A$, in situ hybridization using the antisense probe. $B$, In situ hybridization using the sense probe as a control. C, Hematoxylin staining. Original magnification, $\times 100$.

of colon cancer or primary epithelial cells of normal colon mucosa showed a TR mRNA expression on a very low level (Fig. 7). In contrast, studies with overexpressed Trx represent without doubt a supraphysiologic condition, wherein Trx activates growth but also cell death pathways (Deiss and Kimchi, 1991; Gallegos et al, 1996; Gasdaska et al, 1999a; Hofmann et al, 1998). In addition, our mRNA data were supported by analysis of protein expression. Normal colonic crypt cells (Fig. 9A) as well as the corresponding neoplastic colonic crypt cells (Fig. 9C) showed no immunoreactivity TR1, whereas stromal cells of normal (Fig. 9A) and malignant tissue sections (Fig. 9C) showed a clear immunoreactivity for TR1.

The mechanism(s) underlying the loss of TR1positive/CD3-positive/CD56-positive cells or the resulting biologic consequence of this phenomenon observed in neoplastic colonic tissue is unclear. Although the downstream molecular events that medi-

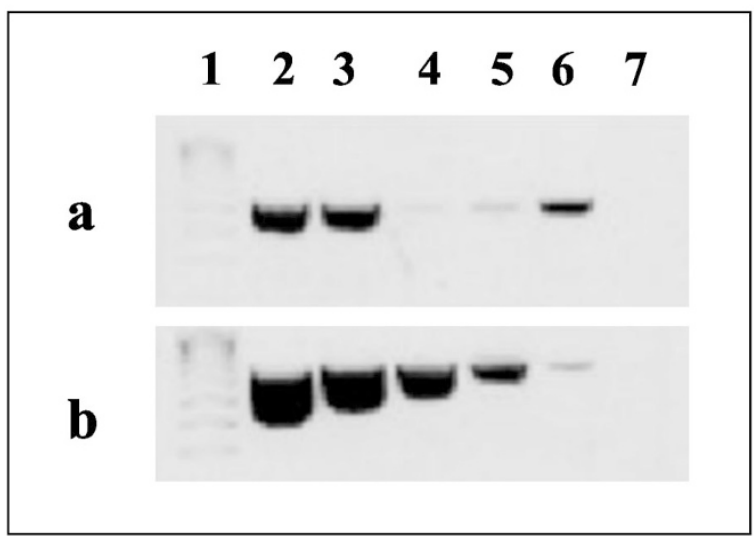

\section{Figure 7.}

Expression of TR1 mRNA of the colon cancer cell line HT-29, the fibrosarcoma cell line HT 1080, and microdissected (laser capture microdissection) epithelial cells of colon cancer tissue analyzed by RT-PCR. 1, marker 100-bp ladder; 2, HT1080 1 ng RNA; 3, HT-29 1 ng RNA; 4, HT1080 50 pg RNA; 5, HT-29 50 pg RNA; 6, microdissected colonic crypts (tumor); 7, negative control. a, $18 \mathrm{~S}$ (488 bp). b, TR1 (601 bp). The PCR reaction was performed as a multiplex PCR (18S and TR1).

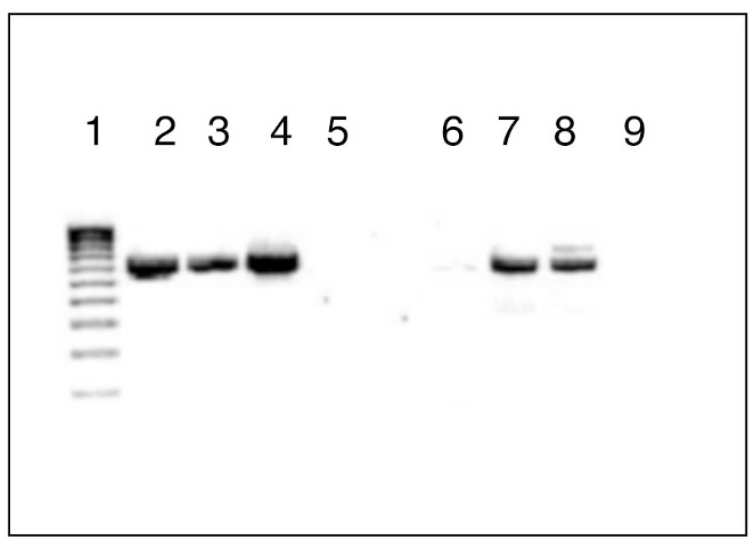

Figure 8.

Expression of TR1 mRNA of intestinal epithelial cells (IEC; = IEC of normal colon mucosa), the colon cancer cell line HT-29, and the fibrosarcoma cell line HT 1080 analyzed by RT-PCR. 1, marker 100-bp ladder; 2, IEC; 3, HT-29 1; 4 , HT1080; 5 , negative control; $2-5, \beta$-actin (600 bp); $6-9$, TR1 (601 bp). The PCR reaction was performed as a multiplex PCR ( $\beta$-actin and TR1).

ate TR-Trx-induced growth inhibition or cell death are being investigated, recent studies illustrate novel mechanisms of cell death involving oxidoreductases. One possibility is that Trx may influence the interferon (IFN)-induced inhibitory growth pathway via modulation of Janus kinase function. The function of the latter is strongly dependent on the redox status (Duhe et al, 1998). Similarly, suppression of Trx levels seems to ablate growth-inhibitory effects of IFN- $\gamma$ (Deiss and Kimchi, 1991). Interference with Janus kinase function inhibits the ability of IFNs to induce growth-regulatory genes such as IL-1 $\beta$-converting enzyme or WAF/Cip1 (Chin et al, 1996, 1997) and therefore enhances cell survival. A recent paper suggested that increased growth in MCF-7 cells overexpressing Trx is not mediated by increased activation of the transcription factor NF- $\kappa$ B (Freemerman et al, 1999). In addition, $\mathrm{AP}-1$, another transcription factor associated with 

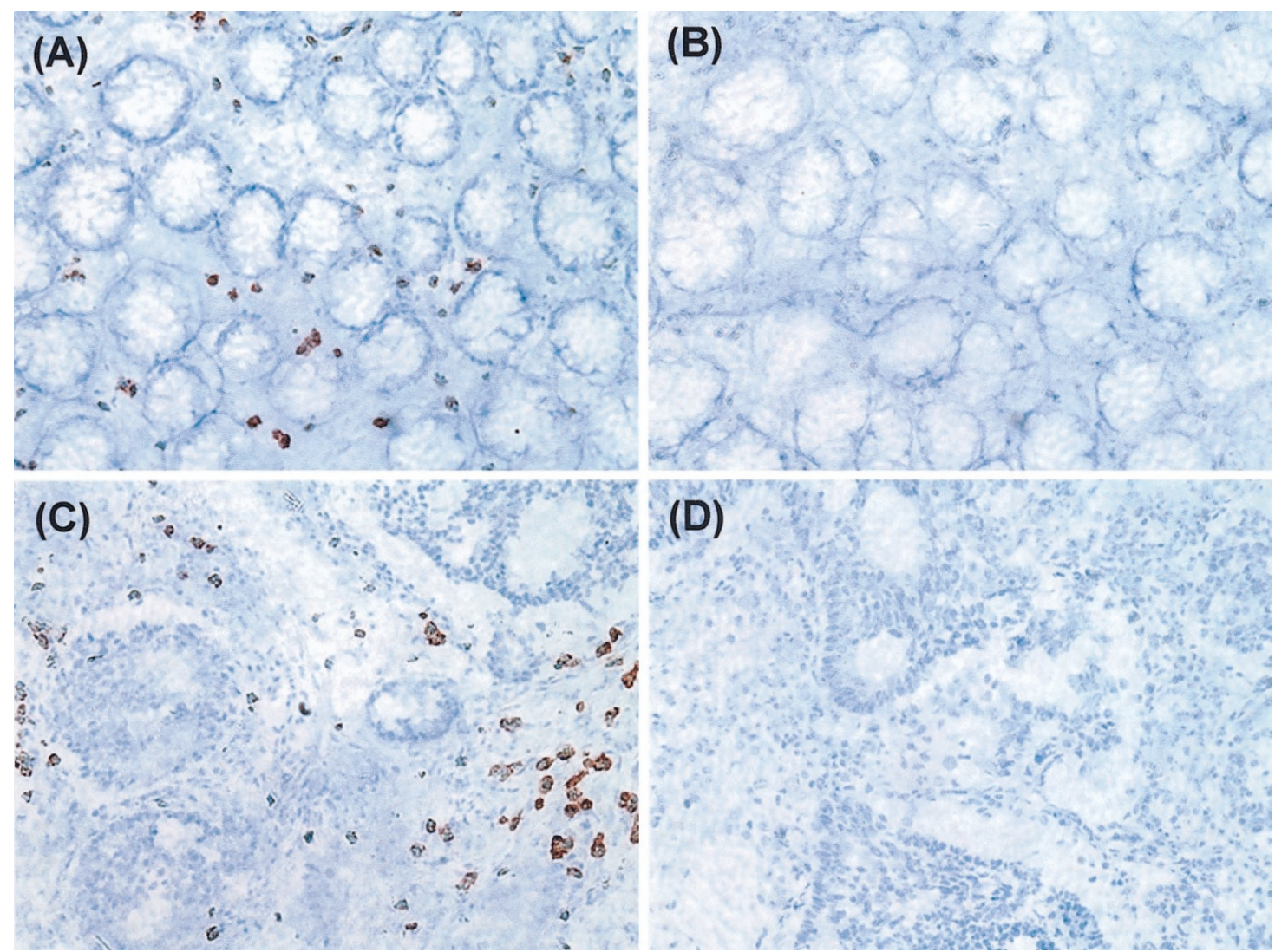

Figure 9.

Immunohistochemical staining using an antibody against TR1. A and B, Normal colonic tissue. $\mathrm{C}$ and D, Corresponding malignant tissue. TR1 protein-positive cells exhibit a red/brown staining (A and $C)$. B and D, Negative control. In addition, our mRNA data were supported by analysis of protein expression. Normal colonic crypt cells (A) as well as the neoplastic colonic crypt cells $(C)$ show no immunoreactivity for TR1, whereas stromal cells were TR1 positive for both. Original magnification, $\times 100$.

growth, was increased up to 10-fold in Trxoverexpressing cells. Thus, AP-1 activation might contribute to the growth-promoting effect of Trx (Freemerman et al, 1999).

In summary, this study showed that epithelial cells in normal, inflammatory, or neoplastic colonic mucosa do not express a relevant amount of TR1 mRNA and protein. TR-positive cells are localized between the crypts of normal colonic crypts and are partially CD3 and CD56 positive. In neoplastic areas of colonic cancer tissue, a loss of TR1-positive cells in the stroma was obvious. On the basis of the presented data, there is no evidence that TR1 plays a significant role in vivo in normal cell growth processes in colonic epithelial cells, in contrast to in vitro findings. The mechanism underlying the loss of TR1-positive/CD3positive/CD56-positive cells or the biologic consequence of this phenomenon observed in neoplastic colonic tissue remains to be clarified.

\section{Materials and Methods}

\section{Colonic Tissue, Isolation of Primary Large Intestinal Epithelial Cells, and Cell Culture}

Human colorectal tumors $(n=4)$ and corresponding normal mucosa, two adenomatous polyps, and two colonic tissues of patients with Crohn's disease were obtained as excess surgical material from the University of Regensburg operating rooms. The tissue was analyzed microscopically by a pathologist. The study was approved by the ethical committee of the University of Regensburg and performed in accordance with the Helsinki declaration.

For the isolation of primary large intestinal epithelial cells (IEC), the mucosa was stripped from the submucosa within 30 minutes after bowel resection and rinsed with PBS several times. The mucus was removed by treatment with $1 \mathrm{~mm}$ dithiothreitol (Serva, Heidelberg, Germany) for 15 minutes. After washing with PBS, the mucosa was placed in $1.5 \mathrm{~mm}$ EDTA in Hanks' balanced salt solution without calcium and magnesium and tumbled for 10 minutes at $37^{\circ} \mathrm{C}$. This supernatant, containing debris and mainly villus cells, was discarded. The mucosa was incubated again with EDTA for 10 minutes at $37^{\circ} \mathrm{C}$. The supernatant was collected into a $15-\mathrm{ml}$ tube. Next, the remaining mucosa was vortexed in PBS. This supernatant was also collected; it contained complete crypts, some single cells, and a small amount of debris. For separating IEC (crypts) from contaminating nonepithelial cells (eg, intraepithelial lymphocytes), the suspension was allowed to sediment for 15 minutes. The sedimented cells (mainly complete crypts) were collected and washed twice with PBS. With the use of the isolation 
technique, $>90 \%$ of cells are EP4-positive (IEC) and $<10 \%$ are of nonepithelial origin, including macrophages and lymphocytes.

Cell lines were obtained from the Deutsche Sammlung für Mikroorganismen und Zellkulturen GmbH (Braunschweig, Germany) or the American Tissue Type Collection (Rockville, Maryland). The gastric cancer cell line 23132/87 and the colon cancer cell lines LoVo, HCT-15, SW480, and SW620 were grown in RPMI 1640 (Gibco BRL, Grand Island, New York); the colon cancer cell line HT-29, A549 (lung cancer), HT1080 (fibrosarcoma), Caki1 (kidney cancer), and the normal cells (scleroderma fibroblasts SKDE, colonic fibroblasts and keratinocytes $\mathrm{HaCa}$ ) were grown in DMEM (Biochrom, Berlin, Germany); and the breast cancer line BT20 in was grown in Eagle's MEM 90\% (Biochrom). Media were supplemented with 10\% FCS (Gibco BRL) and 1\% penicillin/streptomycin (PAA Laboratories $\mathrm{GmbH}$, Linz, Austria). Cells were grown in monolayers and $70 \%$ confluence at $37^{\circ} \mathrm{C}$ in $10 \%$ $\mathrm{CO}_{2}$.

\section{Generation of Spheroids}

Spheroids were generated according to the liquid overlay culture technique. Epithelial cells $\left(4 \times 10^{3}\right)$ suspended in $0.2 \mathrm{ml}$ of medium/well were seeded in agarose-coated 96-well plates and cultured under static conditions. The cells formed small aggregates within 24 hours, which enlarged during further culture. Every 2 days, half of the medium was replaced by fresh medium. After 6 and 11 days, aggregates were harvested for the subsequent experiments and embedded in medium (OCT Tissue Tek, VWR Scientific Products Corporation, San Diego, California) for cryosections and frozen in liquid nitrogen.

\section{Tumor Formation of HT-29 Cells in SCID Mice}

Female Crl-scidBR mice, 4 weeks of age, were purchased from Charles River (Sulzfeld, Germany) and housed under Institutional Animal Care and Use Committee-approved germ-free conditions.

HT-29 cells were cultivated as described above. Immediately before implantation, the cells were trypsinized, spun down, and counted. Approximately $10^{6}$ cells were resuspended in saline solution in a final volume of approximately $100 \mu \mathrm{l}$.

Injection of the cells under the skin at the left flank of the SCID mouse was performed under sterile conditions. After 4 weeks, large tumors could be detected, were explanted, and were snap-frozen.

\section{Tissue Sections}

Fresh colonic tissue was already placed in the operating room immediately after the surgical procedure in embedding medium (OCT Tissue Tek) and cryofrozen in n-buthanol, which was cooled down by liquid nitrogen as outlined previously (Kullmann et al, 1999). All cryoblocks were stored at $-80^{\circ} \mathrm{C}$ until cutting.

Glass slides were membrane-mounted (PEN membrane; P.A.L.M., Wolfratshausen, Germany) and poly-
L-lysin coated $(0.2 \%$ in sterile, diethylpyrocarbonatetreated $\mathrm{H}_{2} \mathrm{O}$ ) under RNAse-free conditions. Cryosections (4 to $6 \mu \mathrm{m}$ ) were cut in a cryostat and fixed. For laser-mediated microdissection, they were dehydrated with ethanol/acetic acid (20/1); for immunohistochemistry, they were dehydrated with acetone; and for in situ hybridization, they were fixed with paraformaldehyde (3\%).

\section{Laser-Mediated Microdissection}

Laser-mediated microdissection was performed using a Robot Microbeam laser microscope (P.A.L.M.) as described previously (Lechner et al, 2001). Briefly, the area of interest was positioned according to the analysis of the pathologist and cut out using a focused, pulsed laser beam. Dissected areas were collected in the cap of a microcentrifuge tube by automatic laser pressure catapulting. With the use of a high-energy, defocused, short-duration laser pulse, the object of interest was catapulted off the slide, facilitated by coating the slide with the PEN membrane. The cap with the dissected tissue was immediately placed on the microfuge tube containing $300 \mu$ l of RLT lysis buffer of the RNeasy spin column purification kit (Qiagen, Hilden, Germany), and tissue was lysed by mixing. In total, we isolated 40 crypts of the colon (only epithelial cells) for our experiments.

\section{RNA Extraction}

Cultured cells were washed and directly lysed on the plate. Total cellular RNA was extracted using the RNeasy spin column purification kit (Qiagen). For removing the remaining genomic DNA, total RNA was treated with DNase I (Boehringer Mannheim, Mannheim, Germany) for 40 minutes at $37^{\circ} \mathrm{C}$. RNA concentrations were measured using the Riobogreen RNA quantification kit (Molecular Probes, Leiden, Netherlands).

\section{RT-PCR of TR1}

Semiquantitative RT-PCR of cell line RNA was performed using the QuantumRNA module (Ambion, Austin, Texas) for confirmation of differential gene expression. 18S rRNA primers, which amplify a 488-bp fragment, were used as multiplex-PCR together with TR1-specific primers (TR_F 5'-CGATCTGCCCGTTGTGTTTG-3' and TR_B 5'-CAAGTAACGTGGTCTTTCACCAGTG-3'). These were designed amplifying a 601-bp fragment of the TR1 gene (bp 32 to bp 633). With the use of this technique, relative transcript abundances can be compared following standardization of the co-amplified 18S rRNA RT-PCR product as an internal standard. PCR conditions were chosen to allow amplification in the exponential phase. For that purpose, competing primers for 18S rRNA amplification of which the $3^{\prime}$ end is blocked, so-called competimers, were titrated to allow amplification of the abundant $18 \mathrm{~S}$ cDNA template in the exponential phase. Avian myeloblastosis virus reverse transcriptase (Gibco BRL) was used for cDNA synthesis, and 
AmpliTaq (Gibco BRL) was used for amplification. Radioactive PCR products of simultaneously amplified TR and 18S cDNA templates were analyzed on a $4 \%$ to $20 \%$ TBE gel (Novex, Frankfurt, Germany). Evaluation was done by phosphor imaging densitometry (Phosphor Imager; Molecular Dynamics, Sunnyvale, California), and subsequent data analysis was performed using the Ambis software (ImageQuant, Molecular Dynamics).

Microdissected tissue samples were amplified using the QuantumRNA module (Ambion) or the Titan One Tube RT-PCR System (Roche, Mannheim, Germany) following the manufacturer's standard protocol. Reverse transcription was carried out at $50^{\circ} \mathrm{C}$ for 30 minutes, directly followed by the PCR. The PCR conditions were 40 cycles of $95^{\circ} \mathrm{C} / 5$ seconds, $59^{\circ} \mathrm{C} /$ 30 seconds, and $72^{\circ} \mathrm{C} / 60$ seconds with a 7 -minute extension after the last cycle. PCR products were fractionated by electrophoresis in 1\% agarose gels.

\section{In Situ Hybridization}

Plasmids containing a 601-bp TR1 cDNA fragment were linearized by digestion with EcoRV or BamH1. Antisense and sense RNA probes were transcribed by SP6 and T7 RNA polymerase (Stratagene, San Diego, California), including digoxigenin-UTP for labeling (Boehringer Mannheim). Cells were grown in chamber slides coated with $0.01 \%$ poly-L-lysine, and frozen sections (4 to $6 \mu \mathrm{m}$ thick) were cut. First, sections and cells were fixed in $3 \%$ buffered paraformaldehyde for 1 hour at room temperature $\left(20^{\circ} \mathrm{C}\right.$ to $\left.22^{\circ} \mathrm{C}\right)$. Slides were rinsed in $2 \times \mathrm{SSC}(0.3 \mathrm{M} \mathrm{NaCl}, 0.03 \mathrm{M}$ sodium citrate) followed by incubation in $2 \times$ SSC, $0.1 \mathrm{M}$ triethanolamine- $\mathrm{HCl}(\mathrm{pH}$ 8.0; Sigma, St. Louis, Missouri), and $0.25 \%$ acetic anhydride (Fisher Scientific, Springfield, New Jersey) for 18 minutes at room temperature. After a rinsing step with $0.1 \mathrm{M}$ triethanolamine- $\mathrm{HCl}(\mathrm{pH} 8.0)$, the prehybridization was performed in a prehybridization buffer containing 2.5 $\mathrm{ml}$ of formamide (Sigma), $1 \mathrm{ml}$ of $20 \times$ SSC, $0.1 \mathrm{ml}$ of $50 \times$ Denhardt's solution (Sigma), $0.25 \mathrm{ml}$ of denatured herring sperm DNA (10 mg/ml; Sigma), $0.125 \mathrm{ml}$ of yeast tRNA (10 mg/ml; Boehringer Mannheim), and 1 $\mathrm{ml}$ of dextran sulfate (50\%; Sigma). After hybridization, digoxigenin-labeled antisense or sense probe (as control) was applied to the slide. The slides were hybridized for 12 hours at $52^{\circ} \mathrm{C}$. Then slides were washed, twice with $2 \times$ SSC and once with STE $(500 \mathrm{~mm} \mathrm{NaCl}$, $1 \mathrm{~mm}$ EDTA, $20 \mathrm{~mm}$ Tris/HCl [pH 7.6]). After digestion for 1 hour at $37^{\circ} \mathrm{C}$ using $20 \mu \mathrm{g} / \mathrm{ml}$ RNAseA (Boehringer Mannheim), slides were rinsed with $2 \times \mathrm{SSC}$, $50 \%$ formamide for 5 minutes, followed by $1 \times$ SSC, $0.1 \%$ SDS for 10 minutes, and $0.5 \times$ SSC, $0.1 \%$ SDS for 15 minutes. Stringent washes were performed at $50^{\circ} \mathrm{C}$. The slides were washed with $0.1 \mathrm{M}$ Tris $/ \mathrm{NaCl}$ $(\mathrm{pH}$ 7.6) and incubated in $0.1 \mathrm{M}$ Tris/NaCl $(\mathrm{pH} 7.6)$ containing $2 \%$ normal horse serum to block nonspecific binding for 30 minutes at room temperature followed by incubation with anti-digoxigenin-APOantibody-complex (Boehringer Mannheim) in $0.1 \mathrm{M}$ Tris/NaCl $(\mathrm{pH} 7.6)$ containing 1\% normal horse serum and mounted. After rinsing in Tris/ $\mathrm{NaCl}(\mathrm{pH} 9.7)$, color development was performed using the new fuchsin method kit (Dako, Carpinteria, California). The hybridization were repeated four times for every slide.

\section{Immunohistochemistry}

Immunohistochemistry was performed with monoclonal mouse anti-human TR1 (Mabtech, Hamburg, Germany), anti-human CD3, anti-human CD45, antihuman CD68, anti-human collagen type IV (all DAKO, Hamburg, Germany), and anti-human CD56-antibody (Coulter) using the 3-amino-9-ethylcarbazole substrate kit for peroxidase (Vector Laboratories, Burlingame, California). Snap-frozen sections were cut (4 to $6 \mu \mathrm{m})$, fixed for 5 minutes in acetone, and covered with a $4 \%$ nonfat dry milk, $2 \%$ normal goat serum buffer for 30 minutes at room temperature to block nonspecific binding. After rinsing in Tris/ $\mathrm{NaCl}(\mathrm{pH} 7.6)$, the slides were incubated for 45 minutes at room temperature with the primary antibodies diluted 1:50 to $1: 200$ in Tris/ $\mathrm{NaCl}(\mathrm{pH} 7.6)$ containing $2 \%$ nonfat dry milk. The slides were rinsed in Tris/ $\mathrm{NaCl}(\mathrm{pH} 7.6)$ and incubated for 30 minutes at room temperature with a secondary biotinylated goat anti-mouse antibody (Pharmingen) diluted 1:600 in Tris/ $\mathrm{NaCl}(\mathrm{pH} 7.6)$ containing $2 \%$ nonfat dry milk. Incubation with the 3-amino-9-ethylcarbazole substrate was performed for 30 minutes at room temperature. The color development (varying from 10 to 30 minutes) was stopped after microscopic examination by washing with water. After staining with hematoxylin, the slides were mounted immediately (Gel Mount; Biomeda, Foster City, California).

\section{Acknowledgement}

The expert help of Wibke Ballhorn in in situ hybridization and immunohistochemistry experiments is gratefully acknowledged.

\section{References}

Abate C, Patel L, Rauscher FJ, and Curran T (1990). Redox regulation of fos and jun DNA-binding activity in vitro. Science 249:1157-1161.

Baker A, Payne CM, Briehl MM, and Powis G (1997). Thioredoxin, a gene found overexpressed in human cancer, inhibits apoptosis in vitro and in vivo. Cancer Res 57:5162-5167.

Bannister AJ, Cook A, and Kouzarides T (1991). In vitro DNA binding activity of Fos/Jun and BZLF1 but not C/EBP is affected by redox changes. Oncogene 6:1243-1250.

Berggren M, Gallegos A, Gasdaska JR, Gasdaska PY, Warneke J, and Powis G (1996). Thioredoxin and thioredoxin reductase gene expression in human tumors and cell lines, and the effects of serum stimulation and hypoxia. Anticancer Res 16:3459-3466.

Berggren M, Gallegos A, Gasdaska J, and Powis G (1997). Cellular thioredoxin reductase activity is regulated by selenium. Anticancer Res 17:3377-3380. 
Chin YE, Kitagawa M, Kuida K, Flavell RA, and Fu XY (1997). Activation of the STAT signaling pathway can cause expression of caspase 1 and apoptosis. Mol Cell Biol 17:53285337.

Chin YE, Kitagawa M, Su WC, You ZH, Iwamoto Y, and Fu XY (1996). Cell growth arrest and induction of cyclin-dependent kinase inhibitor p21 WAF1/CIP1 mediated by STAT1. Science 272:719-722.

Cromlish JA and Roeder RG (1989). Human transcription factor IIIC (TFIIIC). Purification, polypeptide structure, and the involvement of thiol groups in specific DNA binding. $J$ Biol Chem 264:18100-18109.

Deiss LP and Kimchi A (1991). A genetic tool used to identify thioredoxin as a mediator of a growth inhibitory signal. Science 252:117-120.

Duhe RJ, Evans GA, Erwin RA, Kirken RA, Cox GW, and Farrar WL (1998). Nitric oxide and thiol redox regulation of Janus kinase activity. Proc Natl Acad Sci USA 95:126-131.

Freemerman AJ, Gallegos A, and Powis G (1999). Nuclear factor kappaB transactivation is increased but is not involved in the proliferative effects of thioredoxin overexpression in MCF-7 breast cancer cells. Cancer Res 59:4090-4094.

Gallegos A, Berggren M, Gasdaska JR, and Powis G (1997). Mechanisms of the regulation of thioredoxin reductase activity in cancer cells by the chemopreventive agent selenium. Cancer Res 57:4965-4970.

Gallegos A, Gasdaska JR, Taylor CW, Paine-Murrieta GD, Goodman D, Gasdaska PY, Berggren M, Briehl MM, and Powis G (1996). Transfection with human thioredoxin increases cell proliferation and a dominant-negative mutant thioredoxin reverses the transformed phenotype of human breast cancer cells. Cancer Res 56:5765-5770.

Gasdaska JR, Berggren M, and Powis G (1995a). Cell growth stimulation by the redox protein thioredoxin occurs by a novel helper mechanism. Cell Growth Differ 6:1643-1650.

Gasdaska JR, Gasdaska PY, Gallegos A, and Powis G (1996). Human thioredoxin reductase gene localization to chromosomal position 12q23-q24.1 and mRNA distribution in human tissue. Genomics 37:257-259.

Gasdaska JR, Harney JW, Gasdaska PY, Powis G, and Berry MJ (1999a). Regulation of human thioredoxin reductase expression and activity by 3 '-untranslated region selenocysteine insertion sequence and mRNA instability elements. J Biol Chem 274:25379-25385.

Gasdaska PY, Berggren MM, Berry MJ, and Powis G (1999b). Cloning, sequencing and functional expression of a novel human thioredoxin reductase. FEBS Lett 442:105-111.

Gasdaska PY, Gasdaska JR, Cochran S, and Powis G (1995b). Cloning and sequencing of a human thioredoxin reductase. FEBS Lett 373:5-9.

Grippo JF, Holmgren A, and Pratt WB (1985). Proof that the endogenous, heat-stable glucocorticoid receptor-activating factor is thioredoxin. J Biol Chem 260:93-97.

Hadley KB and Sunde RA (2001). Selenium regulation of thioredoxin reductase and mRNA levels in rat liver. $J$ Nutr Biochem 12:693-702.

Hara S, Shoji Y, Sakurai A, Yuasa K, Himeno S, and Imura N (2001). Effects of selenium deficiency on expression of selenoproteins in bovine arterial endothelial cells. Biol Pharm Bull 24:754-759.
Hirota K, Murata M, Sachi Y, Nakamura H, Takeuchi J, Mori $\mathrm{K}$, and Yodoi $\mathrm{J}$ (1999). Distinct roles of thioredoxin in the cytoplasm and in the nucleus. A two-step mechanism of redox regulation of transcription factor NF-kappaB. J Biol Chem 274:27891-27897.

Hofmann ER, Boyanapalli M, Lindner DJ, Weihua X, Hassel BA, Jagus R, Gutierrez PL, Kalvakolanu DV, and Hofman ER (1998). Thioredoxin reductase mediates cell death effects of the combination of beta interferon and retinoic acid. Mol Cell Biol 18:6493-6504.

Hu J, Ma X, Lindner DJ, Karra S, Hofmann ER, Reddy SP, and Kalvakolanu DV (2001). Modulation of p53 dependent gene expression and cell death through thioredoxinthioredoxin reductase by the interferon-retinoid combination. Oncogene 20:4235-4248.

Karimpour S, Lou J, Lin LL, Rene LM, Lagunas L, Ma X, Karra S, Bradbury CM, Markovina S, Goswami PC, Spitz DR, Hirota K, Kalvakolanu DV, Yodoi J, and Gius D (2002). Thioredoxin reductase regulates $\mathrm{AP}-1$ activity as well as thioredoxin nuclear localization via active cysteines in response to ionizing radiation. Oncogene 21:6317-6327.

Kim MR, Chang HS, Kim BH, Kim S, Baek SH, Kim JH, Lee $\mathrm{SR}$, and Kim JR (2003). Involvements of mitochondrial thioredoxin reductase (TrxR2) in cell proliferation. Biochem Biophys Res Commun 304:119-124.

Kullmann F, Judex M, Ballhorn W, Justen HP, Wessinghage D, Welsh J, Yen TJ, Lang B, Hittle JC, McClelland M, Gay S, Scholmerich J, and Muller-Ladner U (1999). Kinesin-like protein CENP-E is upregulated in rheumatoid synovial fibroblasts. Arthritis Res 1:71-80.

Laurent TC, Moore EC, and Reichard P (1964). Enzymatic synthesis of deoxyribonucleotides. V: Isolation and characterization of thioredoxin, the hydrogen donor from Escherichia coli. B J Biol Chem 239:3436-3444.

Lechner S, Müller-Ladner U, Neumann E, Dietmaier W, Welsh J, Schölmerich J, Rüschoff J, and Kullmann F (2001). Use of simplified transcriptors for the analysis of gene expression profiles in laser micro-dissected cell populations. Lab Invest 81:1233-1242.

Merwin JR, Mustacich DJ, Muller EG, Pearson GD, and Merrill GF (2002). Reporter gene transactivation by human p53 is inhibited in thioredoxin reductase null yeast by a mechanism associated with thioredoxin oxidation and independent of changes in the redox state of glutathione. Carcinogenesis 23:1609-1615.

Miller S, Walker SW, Arthur JR, Lewin MH, Pickard K, Nicol F, Howie AF, and Beckett GJ (2002). Selenoprotein expression in endothelial cells from different human vasculature and species. Biochim Biophys Acta 1588:85-93.

Miranda-Vizuete A, Damdimopoulos AE, Pedrajas JR, Gustafsson JA, and Spyrou G (1999). Human mitochondrial thioredoxin reductase cDNA cloning, expression and genomic organization. Eur J Biochem 261:405-412.

Mustacich D and Powis G (2000). Thioredoxin reductase. Biochem J 346:1-8.

Oblong JE, Berggren M, Gasdaska PY, and Powis G (1994). Site-directed mutagenesis of active site cysteines in human thioredoxin produces competitive inhibitors of human thioredoxin reductase and elimination of mitogenic properties of thioredoxin. J Biol Chem 269:11714-11720. 
Powis G, Briehl M, and Oblong J (1995). Redox signalling and the control of cell growth and death. Pharmacol Ther 68:149173.

Rubartelli A, Bonifaci N, and Sitia R (1995). High rates of thioredoxin secretion correlate with growth arrest in hepatoma cells. Cancer Res 55:675-680.

Sandalova T, Zhong L, Lindqvist $Y$, Holmgren A, and Schneider $G$ (2001). Three-dimensional structure of a mammalian thioredoxin reductase: Implications for mechanism and evolution of a selenocysteine-dependent enzyme. Proc Natl Acad Sci USA 98:9533-9538.

Schallreuter KU, Janner M, Mensing $\mathrm{H}$, Breitbart EW, Berger J, and Wood JM (1991). Thioredoxin reductase activity at the surface of human primary cutaneous melanomas and their surrounding skin. Int J Cancer 48:15-19.

Spyrou G, Enmark E, Miranda-Vizuete A, and Gustafsson J (1997). Cloning and expression of a novel mammalian thioredoxin. J Biol Chem 272:2936-2941.

Tagaya Y, Maeda Y, Mitsui A, Kondo N, Matsui H, Hamuro J, Brown N, Arai K, Yokota T, Wakasugi H, et al (1989). ATL-derived factor (ADF), an IL-2 receptor/Tac inducer homologous to thioredoxin; possible involvement of dithiolreduction in the IL-2 receptor induction. EMBO J 8:757-764.
Wakasugi N, Tagaya Y, Wakasugi H, Mitsui A, Maeda M, Yodoi J, and Tursz T (1990). Adult T-cell leukemia-derived factor/thioredoxin, produced by both human T-lymphotropic virus type I- and Epstein-Barr virus-transformed lymphocytes, acts as an autocrine growth factor and synergizes with interleukin 1 and interleukin 2. Proc Natl Acad Sci USA 87:8282-8286.

Wu Q, Huang K, and Xu H (2003). Effects of long-term selenium deficiency on glutathione peroxidase and thioredoxin reductase activities and expressions in rat aorta. $\mathrm{J}$ Inorg Biochem 94:301-306.

Yodoi J and Tursz T (1991). ADF, a growth-promoting factor derived from adult $T$ cell leukemia and homologous to thioredoxin: Involvement in lymphocyte immortalization by HTLV-I and EBV. Adv Cancer Res 57:381-411. 